\title{
Serum amyloid A protein concentration in bone marrow transplantation for $\beta$ thalassaemia
}

\author{
M Uguccioni, R Meliconi, E Lalli, S Nesci, C Delfini, G Lucarelli, G Gasbarrini, \\ A Facchini
}

\author{
Laboratorio di \\ Immunologia e \\ Genetica, Istituto di \\ Ricerca Codivilla- \\ Putti, Bologna \\ M Uguccioni \\ E Lalli \\ A Facchini \\ Patologia Medica I, \\ Università di Bologna \\ R Meliconi \\ G Gasbarrini \\ Divisione Ematologica \\ di Muraglia, Centro \\ Trapianto Midollo \\ Osseo, Ospedale di \\ Pesaro, Pesaro \\ S Nesci \\ C Delfini \\ G Lucarelli \\ Istituto di \\ Citomorfologia CNR, \\ Chieti, Italy \\ E Lalli \\ Correspondence to: \\ Dr Riccardo Meliconi, \\ I Patologia Medica, \\ Policlinico S.Orsola, vi \\ Massarenti 9, 40138 Bologna, \\ Italy. \\ Accepted for publication \\ 1 October 1991
}

\begin{abstract}
Aims: To investigate whether serum amyloid $A$ protein (SAA) and C-reactive protein (CRP) concentrations could be used in the management of $\beta$ thalassaemic patients undergoing bone marrow transplantation (BMT).

Methods: Serum SAA and CRP concentrations were determined in paired samples from 66 patients with $\beta$ thalassaemia before and after BMT. Serum SAA concentrations were determined by an enzyme linked immunoassay (EIA); serum CRP concentrations were determined by a nephelometric assay.

Results: Serum SAA concentrations before transplantation were significantly higher in the group that subsequently rejected the transplant than the group without complications. SAA concentrations increased after BMT in acute graft versus host disease (GvHD) and rejection. No significant increase in SAA or CRP was found in chronic GvHD. Increases in serum in SAA and CRP concentrations were not related to concomitant infection episodes.

Conclusions: The different acute phase response in acute GvHD and rejection compared with chronic GvHD suggests that different immunopathogenic mechanisms are responsible.
\end{abstract}

Acute phase proteins, and in particular, serum amyloid A protein (SAA) and C-reactive protein (CRP), are currently used to monitor infections and inflammatory processes. Increased serum CRP concentrations after bone marrow transplantation (BMT), carried out for haematological disease other than $\beta$ thalassaemia, have been found in patients with bacterial infections or acute graft versus host disease (GvHD) complicated by infections. But conflicting data about serum CRP concentrations have been reported in acute GvHD without infection. ${ }^{12}$ In chronic GvHD without infection episodes no increase in serum CRP has been found. ${ }^{3}$

SAA is a high density lipoprotein associated plasma protein that is mainly produced in the liver in response to stress or inflammation. It is regulated by the action of cytokines such as interleukin-1 (IL-1), interleukin-6 (IL-6), and tumour necrosis factor (TNF). ${ }^{45}$ Extrahepatic expression of SAA has been shown in virtually all tissues and particularly in those with a recognisable macrophage population. ${ }^{6}$
The rise in SAA blood concentrations that occurs during acute events is the most intense and rapid of all the acute phase proteins.

Little information about serum SAA concentrations after BMT is available. Some studies have been carried out on serum SAA concentrations during renal and liver transplantations which suggest that SAA may be a marker of rejection. ${ }^{78}$

In addition to GvHD, graft failure is one of the events that can occur in $\beta$ thalassaemic transplant recipients. Different factors have been analysed before transplantation to assess their possible influence on outcome. Age, number of transfusions before transplantation, sex of donor/recipient, blood group, removal of spleen, HLA type, and cell dose did not significantly influence the outcome of the transplantation in terms of rejection. In the period immediately after transplantation no precipitating factors for rejection have been identified. ${ }^{9}$

\section{Methods}

Among the series of 222 patients reported elsewhere, ${ }^{1011}$ we randomly selected patients, according to the outcome of $\mathrm{BMT}^{10}: 17$ with acute GvHD; 11 with chronic GvHD; 23 that rejected the transplantation; and 15 disease free survivors.

Of these 66 patients, 22 had received less than or up to 100 transfusions and 44 more than 100 transfusions. The spleens of 16 of these patients had been removed before BMT. Liver biopsy had been carried out in 55 as part of liver disease assessment before BMT. The presence of siderosis and fibrosis was evaluated by semiquantitative scoring: absent, mild, moderate and severe; 15 patients presented with chronic active hepatitis and 13 with chronic persistent hepatitis; none had cirrhosis.

Serum samples were obtained from all patients (mean 31 (SEM) 6) days before BMT and seven to 380 days after transplantation. In patients with GvHD or graft rejection the sample taken after BMT was obtained at the onset of BMT complications. Blood samples were obtained from each patient between 0700 and 0900 hours and left to clot at room temperature. Serum samples were stored at $-70^{\circ} \mathrm{C}$ until analysis. The BMT preparative regimen has been described previously. ${ }^{11}$

\section{EVALUATION AFTER BMT}

Infection was diagnosed on the basis of clinical evaluation, and blood samples were drawn 


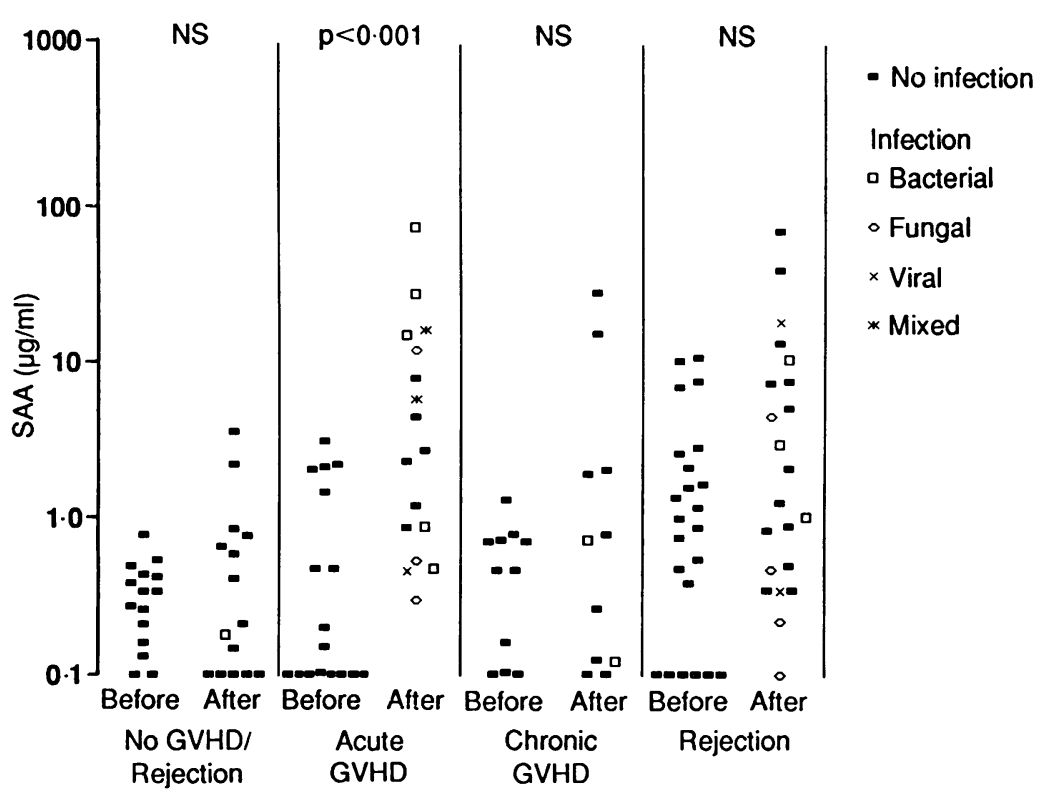

Figure 1 Serum $S A A$ concentrations in $\beta$ thalassaemic patients before and after bone marrow transplantation. whenever the patient had a temperature of $\geqslant 38^{\circ} \mathrm{C}$. Cultures for oral herpes simplex virus and Candida were taken weekly. Documented sepsis was defined as a positive blood culture and a documented fungal infection was defined by positive histological results or a positive culture with appropriate clinical findings. Viral infection was defined by a positive blood culture or a significant increase in IgM class specific antibodies. Acute and chronic GvHD was diagnosed and graded according to established criteria. ${ }^{13}$ Engraftment was evaluated according to $\beta$ chain synthesis or by chromosomal analysis.

\section{SAA ASSAY}

Serum SAA concentrations were determined by an enzyme linked immunoassay (EIA), as reported by Zuckerman and Surprenant, ${ }^{14}$

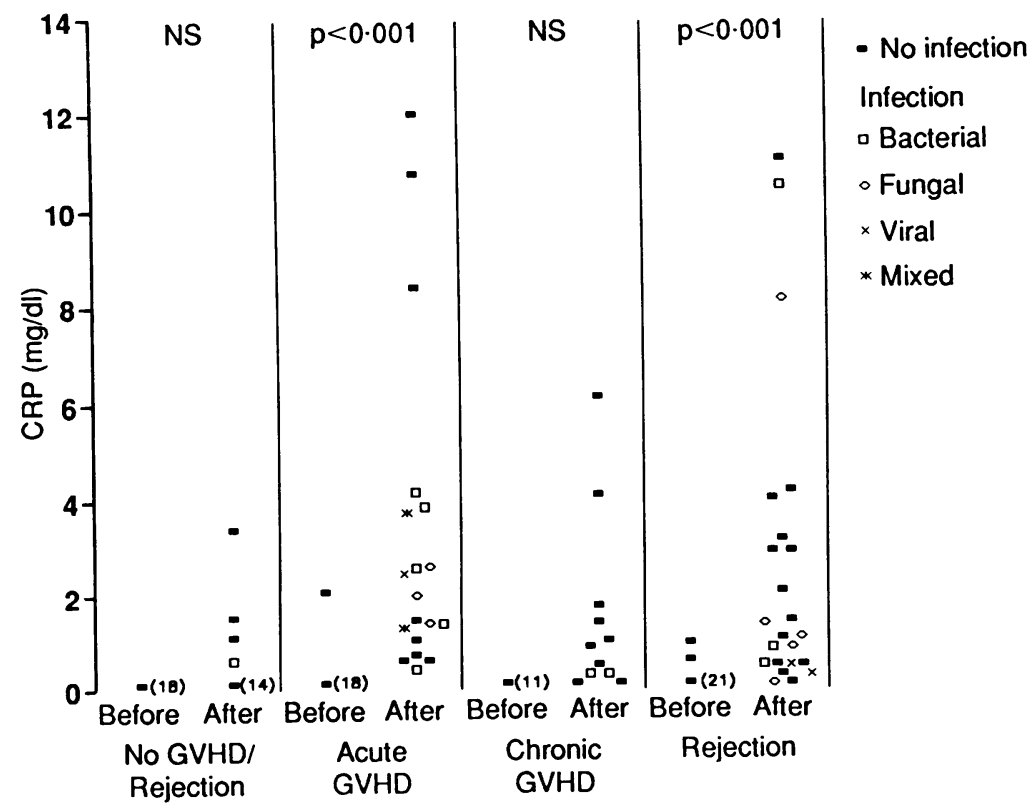

Figure 2 Serum CRP concentrations in $\beta$ thalassaemic patients before and after bone marrow transplantation. with modifications: 96-well plates (Flow, McLean, Virginia, USA) were coated overnight with $100 \mu \mathrm{l}$ of sera diluted in $0 \cdot 1 \mathrm{M}$ sodium bicarbonate, $\mathrm{pH} 9 \cdot 6$, then blocked with $150 \mu \mathrm{l} 5 \%$ dry milk in phosphate buffered saline $(0.05 \%)$ Tween 20 , pH 7.4 (rinse muffer) for one hour at room temperature. After three washes plates were incubated with $100 \mu \mathrm{l}$ rabbit anti-human SAA antiserum (Calbiochem, La Jolla, California, USA), diluted in rinse buffer for 90 minutes at $37^{\circ} \mathrm{C}$. Swine peroxidase-conjugated antirabbit Ig (Dako, Glostrup, Denmark) (100 $\mu \mathrm{l})$ were then added to all wells and incubated for 90 minutes at $37^{\circ} \mathrm{C}$. Following incubation and subsequent washing $75 \mu \mathrm{l}$ of $1 \mathrm{mg} / \mathrm{ml}$ o-phenylendiamine (Sigma, St Louis, Missouri, USA), diluted in $0.1 \mathrm{M}$ phosphate buffer, $\mathrm{pH}$ $6.0+0.05 \% \mathrm{H}_{2} \mathrm{O}_{2}$, were added for $30 \mathrm{~min}$ utes at room temperature. The reaction was blocked with $2 \mathrm{~N} \mathrm{H}_{2} \mathrm{SO}_{4}$ and assorbance at $492 \mathrm{~nm}$ was read with a BIORAD 2550 EIA Reader (Biorad, Richmond, California). Results were quantitated using a rheumatoid arthritis serum pool as a standard, whose SAA content was determined using the method of Godenir et al. ${ }^{15}$

The optical density $v$ SAA concentration was expressed in a logit/log plot. The logit was calculated by normalisation of the optical density, assuming a maximum value equal to " $n$ " times the optical density at the minimum dilution. It was verified that changing this normalisation factor by a factor of 2 causes a variation lower than $1 \%$ in the results.

Serum samples from 20 normal subjects were tested as controls: the mean (2 SD) SAA concentration was $0 \cdot 80(2 \cdot 14) \mu \mathrm{g} / \mathrm{ml}$. Serum CRP concentrations were determined by a nephelometric assay (Beckman Inc, Fullerton, California).

Non-parametric tests were used to analyse data: the Wilcoxon test for paired observations, the Mann-Whitney $U$ test for independent values. The Spearman rank correlation coefficient was used to correlate serum SAA or CRP concentrations and liver histology and serum SAA and CRP concentrations after BMT. A significance level of 0.01 was chosen as significant.

\section{Results}

Serum SAA and CRP concentrations before and after BMT are shown in figs 1 and 2, respectively.

Before transplantation: serum SAA concentrations in $\beta$ thalassaemic patients were higher in the group that subsequently rejected the transplantation than in the group without complications $(p<0.01)$. Serum SAA and CRP concentrations were not related to sex, age, disease duration, number of blood transfusions, transferrin concentrations, degree of liver damage (siderosis, fibrosis, and chronic hepatitis) or drug treatment for engraftment.

After transplantation: Patients with complete recovery did not have increased serum SAA or CRP concentrations. A significant increase in serum SAA $(p<0.001)$ and CRP $(p<0.001)$ 
concentrations was found in patients with acute GvHD.

The increase in serum SAA concentrations did not reach significance in patients with graft rejection, while a significant increase in serum CRP concentrations was found ( $p<0.001)$.

CRP and SAA serum concentrations in acute GvHD or rejection showed significant increases both in patients with and without infections.

After BMT the group of patients that developed chronic GvHD did not show a significant increase in SAA and CRP serum concentrations.

Serum SAA and CRP concentrations after BMT in patients with acute GvHD and rejection were higher $(\mathrm{p}<0.001, \mathrm{p}<0.01)$ (figs 1 and 2) than in patients without complications. Serum concentrations in chronic GvHD were not significantly higher than in patients without complications. CRP and SAA values after transplantation correlated significantly $(\mathrm{Rs}=0.51471, \mathrm{p}<0.001)$

\section{Discussion}

Our results show (1) an increase in serum SAA in the rejection group before BMT; (2) an increase in SAA and CRP during acute GvHD and rejection episodes but no significant increase in serum SAA and CRP during chronic GvHD; (3) and that the increase in serum SAA and CRP in acute GvHD and rejection is not confined to infection episodes.

We found significantly higher serum SAA concentrations before $\mathrm{BMT}$ in $\beta$ thalassaemic patients who subsequently rejected the transplantation, compared with the group without complications. This is an intriguing result and suggests an immune status that may predispose to marrow rejection. Little is known about SAA functions. SAA can exert immunosuppressive activities in vitro: it can inhibit platelet activation, suppress primary antibody response to certain antigens, ${ }^{16}$ and inhibit IL- 1 and TNF induced fever and hypothalamic $\mathrm{PGE}_{2}$ in mice. ${ }^{17}$ On the other hand, recent evidence has shown that SAA synthetised by rabbit synovial fibroblasts may increase collagenase synthesis in the same cells ${ }^{18}$ and this could have a role in the breakdown of the interstitial collagens supporting the inflammatory responses. Therefore, the net effect of circulating SAA is still unknown and it probably varies in different tissues. A prospective study, during which the IL-1, IL-6 and TNF synthetic capability should also be tested, could be useful for understanding the modality of regulation of the acute phase response in $\beta$ thalassaemic patients and in particular the influence of SAA in the immunological abnormalities responsible for marrow rejection. Notably, we recently showed increased TNF concentrations in $\beta$ thalassaemic patients before BMT that was unrelated to the outcome of transplantation. ${ }^{19}$

In acute GvHD and rejection episodes SAA and CRP have shown similar increases even though we failed to find a significant increase in SAA in the group that rejected the transplantation as a result of the higher concentrations before bone marrow infusion. The lack of a significant increase in serum SAA and CRP concentrations in chronic GvHD indicates that different immune effector mechanisms are probably at work in acute and in chronic GvHD. In acute GvHD tissue damage is directly caused by cytotoxic $T$ cells specific for host alloantigens, or by soluble mediators like $\mathrm{TNF} \alpha$, released by $\mathrm{T}$ cells or macrophages. In chronic GvHD $T$ cells specific for common determinants of MHC class II molecules produce unusual patterns of cytokine production such as IL-4 and interferon gamma. This different pattern of cytokine production may explain the lack of a significantly increased APP synthesis during chronic GvHD. ${ }^{20}$

Acute GvHD and rejection episodes are often associated with infections, and previous reports have indicated that increased serum CRP concentrations are a useful marker of bacterial infections ${ }^{1}$ as no increase was seen in GvHD episodes without infections. Conversely, our study shows that in $\beta$ thalassaemic patients an acute phase response is mounted during acute GvHD and marrow rejection independently of the occurrence of infections. Indeed, in a previous study we could not find any correlation between the occurrence of infections and an increase in serum TNF concentration in GvHD and rejection. ${ }^{19}$ This discrepancy could be related to the various immunological abnormalities described in $\beta$ thalassaemia and mainly ascribed to chronic antigenic stimulation (blood transfusions) and iron overload. ${ }^{21-23}$

In conclusion, our study indicates that SAA and CRP testing in patients undergoing BMT for $\beta$ thalassaemia may be of clinical relevance in the detection and management of immunological complications but it offers no information about the occurrence of infections. The suggestion that SAA may represent a marker for identifying candidates for rejection warrants further clinical and experimental validation.

We thank Dr M Baraldini for statistical advice and Mrs Anne Collins for carefully revising the English manuscript.

1 Walker SA, Rogers TR, Riches Pamela G, White S, Hobbs $J R$. Value of serum C-reactive protein measurement in the management of bone marrow transplant recipients. Part I: early transplant period. J Clin Pathol 1984;37:1018.21.

2 Rowe IF, Worsley AM, Donnelly P, et al. Measurement of serum $C$ reactive protein concentration after bone marrow serum C reactive protein concentration after bone marrow transplant

3 Walker SA, Riches Pamela G, Rogers TR, White S, Hobbs JR. Value of serum C-reactive protein measurement in the management of bone marrow transplant recipients. Part II: late post-transplant period. J Clin Pathol 1984;37:1022-6.

4 Vogel SN, Sipe JD. The role of macrophages in the acute phase SAA response to endotoxin. Surv Immunol Res 1982;1:235-41.

5 Ganapathi MK, May LT, Schultz D, et al. Role of interleukin-6 in regulating synthesis of C-reactive protein and serum amyloid $A$ in human and serum amyloid A in human hepatoma

6 Ramadori G, Sipe JD, Colten HR. Expression and regulation of the murine serum amyloid A (SAA) gene in

7 Maury CRJ, Teppo AM. Comparative study of serum amyloid-related protein SAA, C-reactive protein, and $\beta_{2-}$ microglobulin as markers of renal allograft rejection. Clin microglobulin as markers

8 Maury CPJ, Teppo AM, Hockerstedt K. Acute phase proteins and liver allograft rejection. Liver 1988;8:75-9. 9 Galimberti M, Andreani M, Lucarelli G. Patterns of graft 
rejection after bone marrow transplant in thalassemia. In: Advances and controversies in thalassemia therapy: bone marrow transplantation and other approaches. New York: Alan R Liss, Inc, 1989:223-9.

10 Lucarelli G, Galimberti M, Polchi P, et al. Marrow transplantation in patients with advanced thalassemia. $N$ Engl $J$ Med 1987;316:1050-5

11 Lucarelli G, Galimbert $M$, Polchi $P$, et al. Bone marrow transplantation in patients with thalassemia. N Engl J Med 1990;322:417-21.

12 Pocock SJ. Clinical trials. Chichester: John Wiley \& Sons, 983:80-7.

13 Thomas ED, Storb R, Clift RA, et al. Bone-marrow transplantation (second of two parts). N Engl J Med 1975;292:895-902.

14 Zuckerman SH, Surprenant YM. Simplified microELISA for the quantitation of murine serum amyloid A protein. Immunol Methods 1986;92:37-43.

15 Godenir NL, Jeenah MS, Coetzee GA, et al. Standardisation of the quantitation of serum amyloid A protein (SAA) in human serum. $J$ Immunol Methods 1985;83:217-25.

16 Benson MD, Aldo-Benson $M$. Effect of purified protein SAA on immune response in vitro: mechanisms of suppression. Immunol 1979;122:2077-82.

17 Shainkin-Kestenbaum R, Berlyne G, Zimlichman S, Sorin
HR, Nyska M, Danon A. Acute phase protein, serum amyloid $A$, inhibits IL-1- and TNF-induced fever and hypothalassemic $\mathrm{PGE}_{2}$ in mice. Scand $J$ Immenol 1991;34:179-83.

18 Mitchell TI, Coon CI, Brinckerhoff CE. Serum amyloid A (SAA3) produced by rabbit synovial fibroblasts treated with phorbol esters or interleukin 1 induces synthesis of collagenase and is neutralized with specific antiserum.

19 Meliconi R, Uguccioni M, Lalli E, et al. Increased serum concentration of tumour necrosis factor in $\beta$ thalassaemia Effect of bone marrow transplantation. J Clin Patho 1992;45:61-5.

20 Ferrara JLM, Deeg HJ. Graft-versus-host disease. N Engl J Med 1991;324:667-74.

21 Akbar AN, Giardina Patricia J, Hilgarmer W, Gtady RW. Immunological abnormalities in thalassemia major. I. A ransfusion-related in circulating cytoplasmic immunoglobulin positive cells. Clin Exp Immunol 1985;62: 397-404.

22 Neri A, Callea V, D'Ascola DG, Martino B. Immune status in thalassemia major. Haematologica 1986;71:511-16.

23 De Sousa Maria. Immune cell functions in iron overload. Clin Exp Immunol 1989;75:1-6. 